\title{
0885 THE BARELL MATRIX SCOPE OF USE
}

L Aharonson-Daniel* Correspondence: PREPARED Center for Emergency Response Research, Ben-Gurion University of the Negev, P.0. Box 653, Beer Sheva 84105, Israel

10.1136/ip.2010.029215.885

Introduction The Barell matrix proposes a format for epidemiological reports using ICD-9-CM codes. One matrix dimension denotes the body region and the other indicates the nature of injury. The matrix enabled the easy and standard recording and identification of all injuries to a certain body region. It also provides the basis for building multiple injury profiles. After a decade of matrix use, this review examines the literature for applications of the Barell Matrix since its' publication with two aims in mind: To broaden the exposure of the injury community to this important tool and

To demonstrate the broad scope of potential use for injury statistics using this tool.

Methods "Pubmed" and "Google scholar" were searched for the terms "Barell Matrix" "Barell body region by injury nature diagnosis matrix" and "Barell injury diagnosis matrix". Several characteristics for each manuscript were recorded and entered into an excel worksheet. All articles were thoroughly studied to form the following review.

Results 96 applications were included $67.7 \%$ from peer reviewed journals, $28.1 \%$ non peer reviewed, most in formal government publications. The reports originated in 12 countries in five continents written in four languages. The number of annual publications grew from 3 in 2002 to 19 in 2007.76 applications are cited and discussed under various headings such as epidemiology, methodology, health economics, public health agencies and more.

Conclusions The Barell Matrix is increasingly gaining popularity as a tool for standardised injury epidemiology. The broader dissemination of this approach will help boost its' use for the betterment of injury data worldwide. 